\title{
Development of the method for standardization of the medicinal plant raw material of Cichorium intybus L. herb by the total amount of hydroxycinnamic acid derivatives
}

\author{
Kseniya Proskurina ${ }^{1}$, Olga Yevtifieieva ${ }^{2}$, Olga Mala', Viktoriya Mashtaler ${ }^{1}$ \\ 1 Department of Botany, Faculty of Pharmacy, National University of Pharmacy, Kharkiv, 61002, Ukraine \\ 2 Department of Pharmaceutical Chemistry, Faculty of Pharmacy, National University of Pharmacy, Kharkiv, 61002, Ukraine \\ Corresponding author: Kseniya Proskurina (ksenapharm@yahoo.com)
}

Received 11 December 2019 • Accepted 3 February 2020 • Published 20 January 2021

Citation: Proskurina K, Yevtifieieva O, Mala O, Mashtaler V (2021) Development of the method for standardization of the medicinal plant raw material of Cichorium intybus L. herb by the total amount of hydroxycinnamic acid derivatives. Pharmacia 68(1): 167-173. https://doi.org/10.3897/pharmacia.68.e49273

\begin{abstract}
The purpose of the research is to work out a routine method for the quantitative determination of the total amount of hydroxycinnamic acids in chicory herb growing in Ukraine. The presence of chlorogenic and caffeic acids was experimentally proven by comparing the TLC profiles of solutions of the chicory extract and standard substances of hydroxycinnamic acids. According to the chromatogram, the chemical composition of the ethanol extracts was qualitatively constant and did not depend on the series of plants collected in different places (7 regions of Ukraine) and in different years (2017 and 2018). The water-alcohol solutions of 8 chicory herb samples had the absorption maximum at the wavelength range from 326 to $330 \mathrm{~nm}$, which was typical for phenolic acids. Chlorogenic acid was chosen as a marker substance for the quantitative determination by direct spectrophotometry. The value of the specific absorbance $(556.21(\lambda=327 \mathrm{~nm})$ ) of chlorogenic acid in the concentration of $10.08 \mu \mathrm{g} / \mathrm{ml}$ in ethanol $50 \%$ was determined. The total amount of hydroxycinnamic acids was found to be $1.87 \%$ for the sample of 2017 , for the samples of 2018 in the range of $4.00-6.61 \%$. The method proposed is acceptable for standardization of the medicinal plant raw material.
\end{abstract}

\section{Keywords}

Cichorium intybus L., Quantitative Determination, Total Hydroxycinnamic Acid Derivatives, UV-visible Spectrophotometry

\section{Introduction}

Since the $18^{\text {th }}$ century chicory has been appreciated as a medicinal plant in many civilizations for centuries (Kandeler and Ullrich 2009). The medicinal use of chicory was documented in pharmacognosy texts and handbooks dating from 1938 (EMA 2013). Cichorium intybus L. (chicory) has its origins in Europe, Central Russia, Western Asia, and it is also found in Egypt and North America (Bais and
Ravishankar 2001). Nowadays, chicory is widely cultivated in a number of temperate regions around the world (Barcaccia et al. 2016) for numerous food and feed applications: "industrial", "witloof", "leaf" and "forage" (Cadalen et al. 2010). Different parts of chicory or preparations of this plant are used to treat various symptoms and deseases (Street et al. 2013). Chicory has been traditionally applied to treat fever, diarrhea, jaundice and gallstones (Abbas et al. 2015; Pinela et al. 2017). It has been reported 
that chicory possesses the antioxidant (Denev et al. 2014), antihepatotoxic (Ahmed et al. 2008), antidiabetic (Ghamarian et al. 2012) activity. In Ukraine, chicory has been used in folk medicine for treating diabetes, diseases of the liver, biliary tract, kidneys (Yezerska et al. 2014).

Despite this and the long tradition of its use, the medicinal plant raw material of chicory has not been standardized. Chicory has not been described in the European Pharmacopoeia or in any official Pharmacopoeias of the European Union member states (EMA 2013). Chicory herb and roots are only included in the Chinese Pharmacopoeia (ChPh 2005). The State Pharmacopoeia of Ukraine is a full member of the European Pharmacopoeia and has bilateral agreements with the Pharmacopoeia of the United States and the British Pharmacopoeia. For today, the State Pharmacopoeia of Ukraine contains 172 names of the medicinal plant raw material and herbal medicines (SPhU 2014). Based on the national experience in pharmaceutical science the State Pharmacopoeia of Ukraine updates and significantly expands the list of monographs of the medicinal plant raw material. The use of chicory herb as a medicinal plant raw material in medicine requires appropriate approaches to quantify the active components. Therefore, it is relevant to select the necessary quality marker for chicory herb and the routine method, which makes it easy, environmentally friendly, inexpensive, practical, and reliable to assess the quality of the medicinal plant raw material as a potentially pharmacopoeial.

The chemical composition of chicory has been well studied. More than 100 individual compounds were isolated and identified (Street et al. 2013), for this purpose the methods of HPLC, LC / MS, MS / MS were used (Street et al. 2013; Bahri et al. 2012). Isolation and the quantitative determination of all components using HPLC give perfectly reliable results and are indispensable for the qualitative and quantitative study of the multicomponent chemical composition of the plant. On the other hand, when applying any of these methods, one has to deal with more than 10 separate standards for phenolic components. In addition, hazardous and toxic chemicals and solvents that adversely affect the safety of the environment and directly the work of pharmaceutical companies must be used in HPLC methods (Chornyi et al. 2019). The above proves the inefficiency of applying these methods for routine monitoring of the medicinal plant raw material.

The most important activity of chicory is the antioxidant one (Shalini et al. 2014), which is due to such substances as hydroxycinnamic acids and flavonoids. According to the published data, chicory herb contains the following derivatives of hydroxycinnamic acids in large quantities: chlorogenic, neochlorogenic, isochlorogenic, 3-feruloylquinic, 3-n-coumaroylquinic, chicoric, caffeic acids (Yezerska et al. 2014). Therefore, it was decided to standardize the medicinal plant material of chicory by the content of hydroxycinnamic acids. As it can be seen from previously obtained data (Sharma and Dietz 2009; Thirugnanasampandan and Jayakumar 2011), it is impossible to attribute the activity to only one separate component.
Thus, the quantitative assessment of a group of active compounds having the same or similar chemical structure correlates better with the biological activity and is more informative than the quantitative assessment of individual components. In addition, the approach to determining the total amount of active substances is widely used in the pharmacopoeial analysis (EDQM 2013; SPhU 2014). We believe that the spectrophotometric method is appropriate and especially useful for the quantitative standardization of chicory herb as the medicinal plant raw material.

The aim of this work is to develop a routine spectrophotometric method for the quantitative standardization of chicory herb as the medicinal plant raw material growing in Ukraine. The previous qualitative phytochemical analysis is intended to identify the presence and the composition of hydroxycinnamic acids and choose phenolic acid as the standard by which the total amount of hydroxycinnamic acids will be expressed. To determine the amount of hydroxycinnamic acids in the medicinal plant selected it is necessary to develop a procedure using spectrophotometry.

\section{Materials and methods}

\section{Plant material}

Eight samples of chicory herb (Cichorium intybus L.) were used as the research objects, some of them were purchased at the pharmacy, and the rest were collected during the flowering period from May to September in different regions of Ukraine. The data about the series and the place of harvesting and / or manufacturer for the preparation of test solutions are presented in Table 3. The plant species collected was identified and authenticated by professor, Doctor of Pharmacy Gontova T.M. from the Department of Botany, National University of Pharmacy, Ukraine. Aerial parts of the plant were cut into moderately small pieces and dried in shadow at room temperature. The dried herb were kept in a dry place for further phytochemical studies.

\section{Chemicals}

Authentic standards of chlorogenic acid (3-O-caffeoylquinic acid) (CA, $\geq 97,5 \%$ ), caffeic acid (3,4-dihydroxycinnamic acid) (> 99\%), ferulic acid (4-hydroxy-3-methoxycinnamic acid) (99\%) were purchased from Acros Organics BVBA (Janssen Pharmaceuticalaan 3a 2440 Geel, Belgium). Authentic standards of hyperoside (quercetin 3-d-galactoside) (98,23\%), 2-aminoethyl diphenylborinate (97\%), macrogol 400 were purchased from Sigma-Aldrich (Saint Louis, MO, USA). Other reagents and solvents used were of analytical grade.

\section{Thin-layer chromatography analysis}

Phenolic acid was defined by unified pharmacopoeal TLC-methods for identification of phenolic acids (EDQM 2013). The thin-layer chromatographic analysis of pheno- 
lic acids was performed on a precoated silica gel $60 \mathrm{~F}_{254}$ TLC plate (Merck, Germany).

Test solution. To $0.5 \mathrm{~g}$ of the powdered herb (355) (2.9.12) (EDQM 2013) add $10 \mathrm{ml}$ of methanol. Heat on a water-bath at $60{ }^{\circ} \mathrm{C}$ for $5 \mathrm{~min}$. Allow to cool to room temperature and filter.

Reference solution. Dissolve $2.0 \mathrm{mg}$ of chlorogenic acid and $2.0 \mathrm{mg}$ of caffeic acid in $10 \mathrm{ml}$ of methanol.

Mobile phase: Anhydrous formic acid, glacial acetic acid, water, ethyl acetate (11:11:27:100 V/V/V/V).

Application: $10 \mu \mathrm{L}$ as bands of $10 \mathrm{~mm}$.

Drying: in air.

Detection: heat at $100-105{ }^{\circ} \mathrm{C}$ for $5 \mathrm{~min}$; spray the warm plate with $10 \mathrm{~g} / \mathrm{L}$ solution of 2 -aminoethyl diphenylborinate in methanol followed by $50 \mathrm{~g} / \mathrm{L}$ solution of macrogol 400 in methanol; examine in ultraviolet light at $365 \mathrm{~nm}$.

\section{Precision of the TLC method}

The Rf value was calculated for the areas of chlorogenic acid and caffeic acid markers when studying by various analysts for three days. The results were expressed as RSD,\%.

\section{Apparatus}

An UV/Vis a Specord 200 - 220U213 spectrophotometer (Analitik Zena, Germany) and 1-cm quartz cells were used for all absorbance measurements.

\section{Preparation of the test solutions}

Model solution of chlorogenic acid for UV-spectrophotometry: weigh $25 \mathrm{mg}$ of the sample of the standard of chlorogenic acid and dissolve in $100.0 \mathrm{ml}$ of ethanol (50 per cent $\mathrm{V} / \mathrm{V}$ ). Dilute the solution portions of $0.5,1.0,1.5$, 2.0, 2.5, $3.0 \mathrm{ml}$ to $50.0 \mathrm{ml}$ with ethanol ( 50 per cent $\mathrm{V} / \mathrm{V}$ ).

Each solution was measured three times.

\section{Assay of the total amount of hydroxy- cinnamic acids}

To $0.500 \mathrm{~g}$ of the powdered herb add $80 \mathrm{ml}$ of ethanol (50 per cent $\mathrm{V} / \mathrm{V}$ ), and boil the mixture on a water bath under a reflux condenser for $30 \mathrm{~min}$. After cooling, filter the extract, and rinse the filter with $10 \mathrm{ml}$ of ethanol (50 per cent $\mathrm{V} / \mathrm{V})$. Dilute a combined filtrate and the rinsings to 100.0 $\mathrm{ml}$ in a volumetric flask with ethanol (50 per cent V/V), and the resulting solution is used as a stock solution. Prepare the test solution by diluting $2.0 \mathrm{ml}$ of the stock solution to $50.0 \mathrm{ml}$ with ethanol ( 50 per cent $\mathrm{V} / \mathrm{V}$ ). Ethanol (50 per cent $\mathrm{V} / \mathrm{V}$ ) is used as a compensation solution. The absorbance of the test solution is measured immediately at $327 \pm 2 \mathrm{~nm}$.

All analyses were performed in triplicate.

The total amount of hydroxycinnamic acids (X, \%) expressed as chlorogenic acid was calculated according to the formula:

$$
X=\frac{A \times 100.0 \times 50.0 \times 100}{A_{1 c m}^{1 \%} \times 2.0 \times m \times(100-W)}
$$

where $\mathrm{A}$ - is the absorbance of the test solution at $327 \mathrm{~nm}$; $\mathrm{m}$ - is the mass of the powdered herb to be examined, $\mathrm{g}$; $\mathrm{W}$ - is the loss on drying (\%);

$A_{1 \mathrm{~cm}}^{1 \%}$ - is the specific absorption index of chlorogenic acid at $327 \mathrm{~nm}\left(A_{1 \mathrm{~cm}}^{1 \%}=556.21\right)$.

Performance characteristics of the analytical procedures for the total amount of hydroxycinnamic acids were determined taking into account the valuable prevalidation strategy (Grdini'c V. Vukovi'c J. 2004) using model solutions of the standard substance of chlorogenic acid.

\section{Results and discussion}

The presence of hydroxycinnamic acids in ethanolic extracts of aerial parts of chicory was identified using thin-layer chromatography (TLC). The results are presented in Figure 1. The chromatogram shows that the qualitative chemical composition of ethanol extracts is constant and does not depend on the series of plants collected in different places (7 regions of Ukraine) and in different years (2017 and 2018). Four intense areas are found on the chromatogram. Their color indicates that the substances corresponding to them belong to hydroxycinnamic acids. In particular, very intense areas with a greenish-blue fluorescence appear on the chromatogram of the solutions studied; they are at the level of the areas of the standard solutions of chrolenic and caffeic acids. The area of a greenish-blue fluorescence at the top of the chromatogram located below the area of caffeic acid is observed additionally besides the ones already described. Taking into account the results of the earlier studies (Vronska et al. 2016), it can be assumed that this is cichoric acid. According to the chromatogram, hyperoside, a flavonoid, is also present in the composition of the plant, and it is consistent with the data (Street et al. 2013).

The results obtained when determining precision showed that the areas identified on the chromatograms were identical with respect to their number, fluorescence intensity; they were placed in parallel and clearly. The metrological characteristics of determining the areas (Rf) of marker substances for chlorogenic acid were: $\mathrm{Rf}_{\text {average }}=0.483$; RSD $=2.08 \%$; for caffeic acid: $\mathrm{Rf}_{\text {average }}=0.886 ; \mathrm{RSD}=1.15 \%$.

According to Massoud et al. (2009), in chicory leaves caffeic acid was the major phenolic compound presented, followed by chlorogenic, $p$-hydroxybenzoic, $p$-coumaric acids, then protocatechuic, gallic and isovanillic acids in descending order. Our results for identification of chlorogenic and caffeic acids in the samples of the raw material studied correlate with the data (Massoud et al. 2009; Yezerska et al. 2013; Vronska et al. 2016). We selected the hydroxycinnamic acid group as a marker based on the results of thin-layer chromatography; it was found that this 


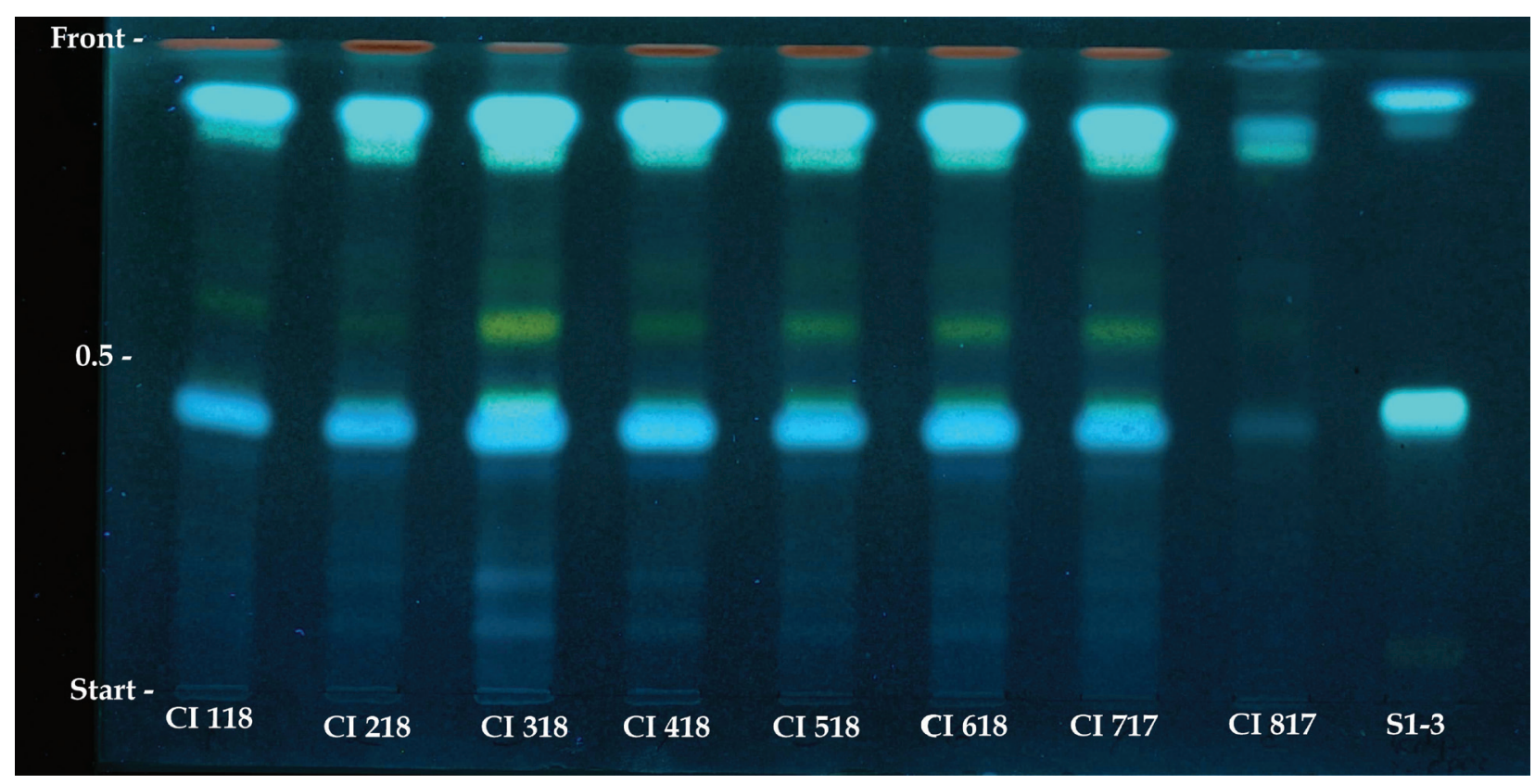

Figure 1. The TLC chromatogram of hydroxycinnamic acids in ethanolic extracts of different samples of chicory herb originating from Ukraine. S1-3: chlorogenic acid, caffeic acid and ferulic acid as references; for plant extracts, see abbreviations in Table 3.

Table 1. The results of the comparative analysis of the sample preparation of methods for the quantitative determination of the total amount of hydroxycinnamic acids in plant objects of the CIS by UV spectrophotometry calculated with reference to the specific absorbance of chlorogenic acid.

\begin{tabular}{|c|c|c|c|c|c|c|c|c|}
\hline \multirow[t]{2}{*}{ No. } & \multirow[t]{2}{*}{ Plant } & \multirow[t]{2}{*}{ Raw material } & \multicolumn{2}{|c|}{ Extraction } & \multirow{2}{*}{$\begin{array}{c}\text { The number of } \\
\text { additional repetitions } \\
\text { of the extraction }\end{array}$} & \multirow{2}{*}{$\begin{array}{c}\text { The wavelength } \\
(\lambda), \mathrm{nm}\end{array}$} & \multirow{2}{*}{$A_{1 \mathrm{~cm}}^{1 \%}$} & \multirow[t]{2}{*}{ Reference } \\
\hline & & & Extractant & $\begin{array}{c}\text { Minutes on a } \\
\text { water bath }\end{array}$ & & & & \\
\hline 1 & Inula helenium $\mathrm{L}$. & roots and rhizomes & ethanol $\left(50^{\mathrm{a}}\right)$ & 45 & $2(15 \mathrm{~min})$. & 325 & 531 & (Vronska et al. 2016) \\
\hline 2 & Cichorium intybus $\mathrm{L}$. & roots & ethanol $\left(50^{\mathrm{a}}\right)$ & 30 & 2 (15 min.) & 325 & 556 & (Yezerska et al. 2013) \\
\hline 3 & Prunus domestica $\mathrm{L}$. & leaves & ethanol $\left(20^{\mathrm{a}}\right)$ & 60 & 1 & 327 & 531 & (Lenchyk 2016) \\
\hline 4 & Polygonum persicaria $\mathrm{L}$. & herb & ethanol $\left(70^{\mathrm{a}}\right)$ & 30 & 1 & 330 & 507 & (Perova et al. 2017) \\
\hline 5 & Urtica dioica $\mathrm{L}$ & leaves & ethanol $\left(70^{\mathrm{a}}\right)$ & 30 & 1 & 328 & 507 & (Trineeva et al. 2015) \\
\hline 6 & Galinsoga parviflora & herb & ethanol $\left(70^{\mathrm{a}}\right)$ & 30 & 0 & 330 & 504 & (Bubenchikova and Boeva 2013) \\
\hline 7 & Cynara scolymus L. & inflorescences & water & 15 & 2 & 327 & 531 & (Fedosov et al. 2017) \\
\hline
\end{tabular}

${ }^{a}$ per cent $\mathrm{V} / \mathrm{V}$.

group was predominant in all plant samples by the intensity of the spots. This was the basis for the development of the method for the quantitative determination of the total amount of hydroxycinnamic acids calculated with reference to a phenolic substance.

The results of the comparative analysis of the methods for the quantitative determination of the total amount of hydroxycinnamic acids by spectrophotometry in various plant objects growing in the territory of the Commonwealth of Independent States (CIS) are presented in Table 1 . Table 1 demonstrates that different concentrations of ethanol and variations with the number of repetitions of extraction are used in the determination. Similarly, the previous studies reported (Yezerska et al. 2013) that the highest absorbance value at maximum absorption of hydroxycinnamic acids, and hence their content, was observed for an extract obtained in ethanol (50 per cent V/V). The same extractant was used for the extraction of hydroxycinnamic acids according to the requirements of the European Pharmacopoeia (EDQM 2013) and the State Pharmacopoeia of Ukraine (SPhU 2014) in the analysis of ash leaves, black horehound, ribwort plantain, rosemary leaves, etc. In the process of the sample preparation ethanol (50 per cent $\mathrm{V} / \mathrm{V}$ ) was used as an extractant of hydroxycinnamic acids according to the requirements of the Pharmacopoeias.

By applying the selected extractant the aqueous alcohol extracts for different samples of chicory herb were obtained. The electronic absorption spectra of this solution are presented in Figure 2. Table 2 demonstrates the results of the study of the electronic absorption spectra of the water-alcohol extracts obtained at the distinct absorption maximum at the wavelength range from 326 to $330 \mathrm{~nm}$, which is characteristic of phenolic acids. It should be noted that, according to Robbins (2003), chlorogenic acid is characterized by the maximum absorption (Amax) at 327 $\mathrm{nm}$, caffeic acid - at $325 \mathrm{~nm}$, chicoric acid - at $330 \mathrm{~nm}$. This makes it possible to directly measure absorption at the maximum, followed by calculation of the content using the specific absorption index in order to determine the total amount of hydroxycinnamic acids.

The aqueous alcoholic solution of chicory is an unstable mixture of substances known and unknown, which to some extent can not only absorb optical density, but also interact with each other. In principle, it is impossible to verify the 


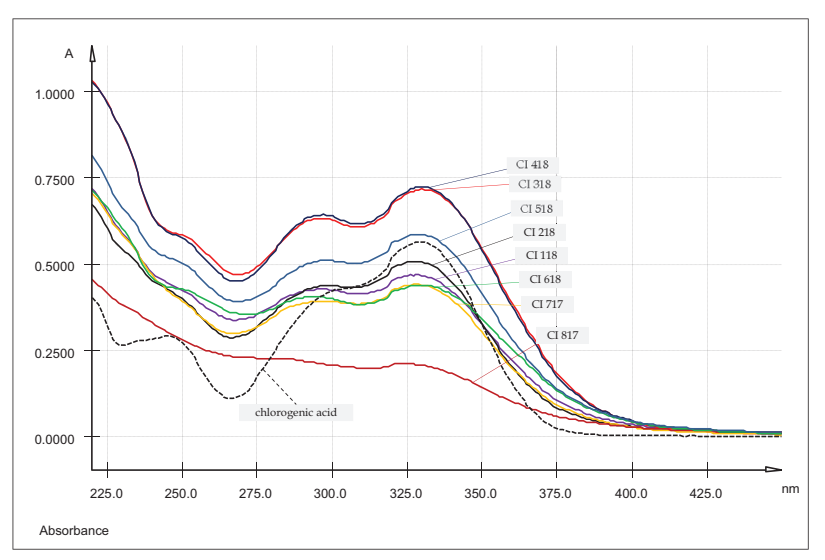

Figure 2. The absorption spectrum of ethanol (50 per cent $\mathrm{V} / \mathrm{V})$ chicory herb extracts for 8 sample of the raw plant material. See abbreviations in Table 3. UV/Vis absorption spectra of chlorogenic acid chemical standard at $10.08 \mu \mathrm{g} / \mathrm{ml}$ in ethanol (50 per cent V/V).

Table 2. The maxima of wavelength of electronic absorption spectra obtained for different samples of chicory herb originating from Ukraine.

\begin{tabular}{|c|c|c|c|c|c|c|c|c|}
\hline \multirow{2}{*}{$\begin{array}{c}\text { No of the } \\
\text { sample }\end{array}$} & \multirow{2}{*}{ Abbr. } & \multicolumn{7}{|c|}{ Maximum absorption ${ }^{\mathrm{a}}$ at a wavelength of } \\
\hline & & $325 \mathrm{~nm}$ & $326 \mathrm{~nm}$ & $327 \mathrm{~nm}$ & $328 \mathrm{~nm}$ & $329 \mathrm{~nm}$ & $330 \mathrm{~nm}$ & $331 \mathrm{~nm}$ \\
\hline 1 & CI 118 & 0.4665 & 0.4688 & 0.4681 & 0.4685 & 0.4685 & 0.4666 & 0.4648 \\
\hline 2 & CI 218 & 0.5056 & 0.5085 & 0.5083 & 0.5083 & 0.5087 & 0.5067 & 0.5042 \\
\hline 3 & CI 318 & 0.7052 & 0.7080 & 0.7118 & 0.7142 & 0.7153 & 0.7170 & 0.7161 \\
\hline 4 & CI 418 & 0.7113 & 0.7173 & 0.7189 & 0.7233 & 0.7234 & 0.7238 & 0.7238 \\
\hline 5 & CI 518 & 0.5811 & 0.5838 & 0.5856 & 0.5863 & 0.5866 & 0.5858 & 0.5855 \\
\hline 6 & CI 618 & 0.4350 & 0.4361 & 0.4363 & 0.4393 & 0.4386 & 0.4392 & 0.4393 \\
\hline 7 & CI 717 & 0.4388 & 0.4401 & 0.4410 & 0.4411 & 0.4414 & 0.4400 & 0.4387 \\
\hline 8 & CI 817 & 0.2106 & 0.2111 & 0.2104 & 0.2098 & 0.2085 & 0.2075 & 0.2063 \\
\hline 9 & Ch.ac. & 0.5485 & 0.5527 & 0.5562 & 0.5583 & 0.5591 & 0.5591 & 0.5574 \\
\hline
\end{tabular}

${ }^{\text {a }}$ Results expressed as average of three independent assays.

additivity of light absorption, i.e. to take into account the influence of other components, mixtures with an incompletely known composition (Vlasova IV et. al. 2011). For more selective determination of substances in spectrophotometry, Folin-Ciocalteu reagents, metal ions (Al (III)), etc., are used. Thus, the European Pharmacopoeia uses the photometric method with the $\mathrm{HCl}-\mathrm{NaNO}_{2}-\mathrm{Na}_{2} \mathrm{MoO}_{4}-$ $\mathrm{NaOH}$ chromogenic system (EDQM 2013). At the same time, according to the data of (Granato D. et al 2016), sodium molybdate can react with mono-, di- and trihydroxyphenols. Taking this into account the photometric method is not so specific since hydroxyl groups contain most phenolic compounds, both hydroxycinnamic acids and flavonoids.

To select a substance for which the content of the total amount of hydroxycinnamic acids was calculated, the absorption spectrum of the solution of the chlorogenic acid standard was measured. The absorption spectrum is presented in Figure 2, which shows that the highest peak is the band at about $327 \mathrm{~nm}(\mathrm{~A}=0.559)$. This band revealed the occurrence of a HOMO/LUMO transition with $\pi \rightarrow \pi^{*}$ character (Cornard et al. 2008). The data obtained correlate with the research results (Navarra et al. 2017). The position of the maximum intensity was highly dependent on the solvent used. In order to take into account the possible contribution of hyperoside to the absorption spectrum of the chicory analytical solution we measured the absorption spectrum of hyperozide in the concentration of $10.0 \mu \mathrm{g} / \mathrm{ml}$. The hyperoside solution had absorption maxima at wavelengths of $256 \mathrm{~nm}$ and $370 \mathrm{~nm}$, and absorption minima - at wavelengths of $242 \mathrm{~nm}, 280 \mathrm{~nm}$ and $320 \mathrm{~nm}$. In the concentration of $10 \mu \mathrm{g} / \mathrm{ml}$ equalled to the solution of chlorogenic acid analyzed the optical absorption of hyperozide at the analytical wavelength 327 $\mathrm{nm}$ was $\mathrm{A}=0.094$; it could be considered as a minor effect. In addition, the intensity of flavonoid spots on the chromatogram (Fig. 1) was much lower than the derivatives of hydroxycinnamic acids. Thus, chlorogenic acid was chosen as a standard for calculating the total amount of hydroxycinnamic acids taking into account its presence in chicory herb both according to the literature data and to the results of the chromatographic research of industrial and growing wild raw samples.

The performance characteristics of the method were previously determined taking into account the valuable validation strategy (Grdini'c V. Vukovi 's J. 2004) using model solutions of the standard substance of chlorogenic acid.

Limiting values, such as the limiting signal value, limit of detection and limit of quantification, were estimated using the analytical evaluation function. The limit of quantification (LOQ) was found to be $0.37 \mu \mathrm{g} / \mathrm{ml}$, while the limit of detection (LOD) was $0.12 \mu \mathrm{g} / \mathrm{ml}$.

The relationship between optical density and the chlorogenic acid content was determined by the least squares method. The linear dependence of the method was described by the equation $y=0.9750 x+0.0264$ and the correlation coefficient $\mathrm{R}^{2}=0.9998$ in the working range from 2.52 to $15.12 \mu \mathrm{g} / \mathrm{ml}$. The standard deviation of the angular coefficient of the linear dependence $\mathrm{Sb}=0.0037$, and the standard deviation of the free term of the linear dependence $\mathrm{Sa}=0.0366$ were also determined.

The following precision parameters were studied: the standard deviation calculated for the "Found / Introduced" ratios for model solutions of chlorogenic acid SD = $0.84 \%$, one-sided confidence interval $\Delta \mathrm{Z}=1.69 \%$.

The determination of the total amount of hydroxycinnamic acids calculated with reference to chlorogenic acid at the wavelength of $325,327,328,330 \mathrm{~nm}$ was reported; it could be substantiated by the different concentration of ethanol during extraction as shown in Table 1. To calculate the total amount of hydroxycinnamic acids different values 504 (Bubenchikova and Boeva 2013), 507 (Trineeva et al. 2015; Trineeva et al. 2015), 531 (Lenchyk 2016; Vronska et al. 2016; Fedosov et al. 2017), 556 (Yezerska et al. 2013) of the specific absorbance of chlorogenic acid were used. Therefore, the specific absorbance value of chlorogenic acid was experimentally determined. Absorbance measurements ( $327 \mathrm{~nm}$, ethanol ( 50 per cent V/V)) for $2.52,5.04,7.56,10.08,12.60,15.12 \mu \mathrm{g} / \mathrm{ml}$ of chlorogenic acid solutions were performed. It was found that the absorbance of chlorogenic acid at $327 \mathrm{~nm}$ followed Beer's law well $(\mathrm{r}=0.9998)$ in the concentration range of 2.5$15.0 \mu \mathrm{g} / \mathrm{ml}$, and it was characterized by the linear equation $y=556.21 \times+0.0015$. This correlation is presented in Fig. 3. The standard deviation (SD) was $0.79 \%$. According 


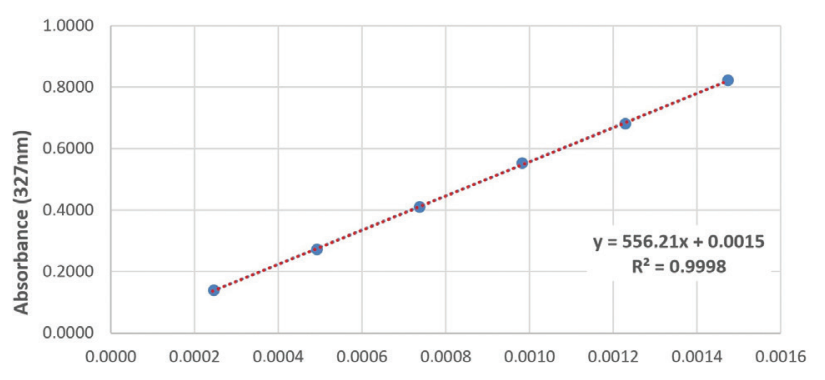

Figure 3. Absorbance values of chlorogenic acid as a function of the solution concentrations. The data correlation was calculated by a linear fit.

to the experimental data, the specific value of the chlorogenic acid absorption was found to be 556.21, and it was used in our calculations.

The samples of chicory herb studied were analyzed using the method developed. The results are presented in Table 3. As can be seen from these results, 7 samples stu-

Table 3. The content of the total amount of hydroxycinnamic acids in chicory herb originating from Ukraine.

\begin{tabular}{llccc}
\hline $\begin{array}{c}\text { No of the } \\
\text { sample }\end{array}$ & \multicolumn{1}{c}{ Region of Ukraine } & $\begin{array}{c}\text { Year of } \\
\text { collection }\end{array}$ & Abbr. & $\begin{array}{c}\text { Content } \\
(\%) \pm \text { SD }^{\mathbf{a}}\end{array}$ \\
\hline 1 & LLC Pharmacy (Kharkiv region) & 2018 & CI 118 & $4.21 \pm 0.14$ \\
2 & Collected wild (Sumy region) & 2018 & CI 218 & $4.57 \pm 0.59$ \\
3 & Collected wild (Kharkiv region) & 2018 & CI 318 & $6.51 \pm 0.73$ \\
4 & "Mir trav" (Zakarpattia region) & 2018 & CI 418 & $6.61 \pm 1.92$ \\
5 & "Lechec" (Kropyvnytskyi region) & 2018 & CI 518 & $5.25 \pm 0.88$ \\
6 & "Kladez Market" (Poltava region) & 2018 & CI 618 & $4.01 \pm 0.21$ \\
7 & LLC Pharmacy (Chernihiv region) & 2017 & CI 717 & $4.00 \pm 0.37$ \\
8 & "Sumyfitofarmacia" Ltd (Sumy region) & 2017 & CI 817 & $1.87 \pm 0.55$ \\
\hline
\end{tabular}

${ }^{\text {a }}$ Results expressed as average \pm standart deviation (SD) of three independent assays. died contain the total amount of hydroxycinnamic acids more than $4.0 \%$. These data correlate with those reported by the authors (Yezerska et al. 2013; Navarra et al. 2017).

\section{Conclusion}

Phenolic substances have been identified by comparing TLC profiles of the ethanol extract of chicory and solutions of standard substances of hydroxycinnamic acids. On the chromatogram of the solutions studied the intense areas with a greenish-blue fluorescence are found at the level of the areas of the standard solutions of chlorogenic and caffeic acids.

The spectrophotometric procedure for the quantitative determination of the total amount of hydroxycinnamic acids calculated with reference to chlorogenic acid has been developed. To estimate the possible influence of environmental factors, the total amount of hydroxycinnamic acids in 8 chicory samples from different regions of Ukraine and different years of collection has been determined. The content of hydroxycinnamic acids is $1.87 \%$ for the chicory sample of 2017 , from $4.00 \%$ to $6.61 \%$ for the samples of 2018. It can be explained by the loss of active substances during storage. The method proposed has several advantages: it is an easy, fast, "greenest" and inexpensive method, available today in most laboratories.

\section{Acknowledgements}

This study was supported by the Ministry of Health of Ukraine (Number of the project: 0114U000949).

\section{References}

Abbas ZK, Shalini S, Mohamed SI, Nahla Z, Hasibur R, Abid AA (2015) Phytochemical, antioxidant and mineral composition of hydroalcoholic extract of chicory (Cichorium intybus L.) leaves. Saudi Journal of Biological Sciences 22(3): 322-326. https://doi.org/10.1016/j. sjbs.2014.11.015

Ahmed B, Khan S, Masood MH, Siddique AH (2008) Anti-hepatotoxic activity of cichotyboside, a sesquiterpene glycoside from the seeds of Cichorium intybus . Journal of Asian Natural Products Research 10(3-4): 223-231. https://doi.org/10.1080/10286020701590764

Bahri M, Hance P, Grec S, Quillet MC, Trotin F, Hilbert JL, Hendriks T (2012) A "novel" protocol for the analysis of hydroxycinnamic acids in leaf tissue of chicory (Cichorium intubus L., Asteraceae). The Scientific World Journal Article ID 142983. https://doi. org/10.1100/2012/142983

Bais HP, Ravishankar GA (2001) Cichorium intybus L - cultivation, processing, utility, value addition and biotechnology, with an emphasis on current status and future prospects. Journal of the Science of Food and Agriculture 81: 467-484. https://doi.org/10.1002/jsfa.817

Barcaccia G, Ghedina A, Lucchin M (2016) Current Advances in Genomics and Breeding of Leaf Chicory (Cichorium intybus L.). Agriculture 6(4): 50-74. https://doi.org/10.3390/agriculture6040050
Bubenchikova VN, Boeva SA (2013) Development and validation of methods of quantitative determination of hydroxycinnamic acids in the grass Galinsoga parviflora. Scientific bulletins of Belgorod State University. Series: Medicine. Pharmacia 25(168): 80-85.

Cadalen T, Mörchen M, Blassiau C, Clabaut A, Scheer I, Hilbert J-L, Hendriks T, Quillet M-C (2010) Development of SSR markers and construction of a consensus genetic map for chicory (Cichorium intybus L.). Molecular Breeding 25: 699-722. https://doi.org/10.1007/ s11032-009-9369-5

Chornyi V, Kushniruk V, Georgiyants V (2019) Design and implementation of green chemistry approaches into pharmaceutical analysis of benzydamine dosage formes. Scientific Journal «ScienceRise: Pharmaceutical Science» 5(21): 12-17. https://doi.org/10.15587/25194852.2019.182024

ChPh [Chinese Pharmacopoeia] (2005) Commission. Pharmacoeia of the people's Republic of China ( $1^{\text {st }}$ ed.). China Medical Science Press, Beiking, ISBN: 978-7-11-706982-3.

Cornard J-P, Lapouge C, Dangleterre L, Allet-Bodelot C (2008) Complexation of lead(II) by chlorogenic acid: Experimental and theoretical study. The Journal of Physical Chemistry A 112(48): 1247512484. https://doi.org/10.1021/jp805463p 
Denev P, Petkova N, Ivanov I, Sirakov B, Vrancheva R, Pavlov A (2014) Determination of biologically active substances in taproot of common chicory (Cichorium intybus L.). Scientific Bulletin. Series F. Biotechnologies XVIII: 124-129.

EDQM [European Directorate for the Quality of Medicines and Health Care] (2013) European Pharmacopoeia ( $8^{\text {th }}$ ed.). Council of Europe, ISBN: 978-92-871-7525-0, Strasbourg, France.

EMA [European Medicines Agency] (2013) "Assessment report on Cichorium intybus L., radix”. EMA/HMPC/113041/2010.

Fedosov AI, Dobrovolnyi OO, Shalamay AS, Novosel OM, Kyslychenko VS (2017) Comparative analysis of hydroxycinnamic acids of Artichoke cultivated in Ukraine and in France. Current issues in pharmacy and medicine: science and practice 10(1): 49-53. https://doi org/10.14739/2409-2932.2017.1.93438

Ghamarian A, Abdollahi M, Su X, Amiri A, Ahadi A, Nowrouzi A (2012) Effect of chicory seed extract on glucose tolerance test (GTT) and metabolic profile in early and late stage diabetic rats. DARU Journal of Pharmaceutical Sciences 20: 56-65. https://doi.org/10.1186/2008-2231-20-56

Kandeler R, Ullrich WR (2009) Symbolism of plants: examples from European-Mediterranean culture presented with biology and history of art. Journal of Experimental Botany 60(14): 3973-3974. https://doi. org/10.1093/jxb/erp248

Lenchyk LV (2016) Determination of Content of Flavonoids, Hydroxycinnamic acids and Volatile compounds in Plum leaves. International journal of advances in pharmacy, biology and chemistry 5(2): 131136. https://doi.org/10.14748/ssp.v2i2.1302

Massoud MI, Amin WA, Elgindy AA (2009) Chemical and Technological Studies on Chicory (Cichorium Intybus L.) and Its Applications in Some Functional Food. Journal of Advance Agricultural Research 14(3): 735-756.

Navarra G, Moschetti M, Guarrasi V, Mangione R, Militello V, Leone M (2017) Simultaneous Determination of Caffeine and Chlorogenic Acids in Green Coffee by UV/Vis Spectroscopy. Journal of Chemistry Article ID 6435086, 8 pp. https://doi.org/10.1155/2017/6435086

Perova IB, Eller KI, Maltseva AA, Chistyakova AS, Slivkin AI, Sorokina AA (2017) Hydroxycinnamic acids of lady's thumb (Polygonum persicaria L.) herb. Pharmacy 5: 27-30.

Pinela J, Carvalho AM, Ferreira ICFR (2017) Wild edible plants: Nutritional and toxicological characteristics, retrieval strategies and importance for today's society. Food and Chemical Toxicology 110: 165-188. https://doi.org/10.1016/j.fct.2017.10.020

Robbins RJ (2003) Phenolic Acids in Foods: An Overview of Analytical Methodology. Journal of Agricultural and Food Chemistry 51(10): 2866-2887. https://doi.org/10.1021/jf026182t

Shalini S, Mohamed IS, Nahla Z, Ehab T, Anand M (2014) Ameliorating effect of chicory (Cichorium intybus L.) fruit extract against 4-tert-octylphenol induced liver injury and oxidative stress in male rats. Food and Chemical Toxicology 72: 138-146. https://doi.org/10.1016/j. fct.2014.06.029

Sharma SS, Dietz KJ (2009) The relationship between metal toxicity and cellular redox imbalance. Trends in Plant Science 14: 43-50. https:// doi.org/10.1016/j.tplants.2008.10.007

SPhU [State Pharmacopoeia of Ukraine: in 3 vols.] (2014) The state enterprise "The Ukrainian scientific pharmacopeial centre of the medicinal products quality". $2^{\text {nd }}$ ed. Kharkiv State Enterprise "Ukrainian Research Center Expert Pharmacopoeia Quality Medicines [in Ukrainian], 3, 732 pp. ISBN 978-966-96478-9-4.

Street RA, Sidana J, Prinsloo G (2013) Cichorium intybus: Traditional Uses, Phytochemistry, Pharmacology, and Toxicology. Evid Based Complement Alternat Med Article ID 579319, 13 pp. https://doi. org/10.1155/2013/579319

Thirugnanasampandan R, Jayakumar R (2011) Protection of cadmium chloride induced DNA damage by Lamiaceae plants. Asian Pacific Journal of Tropical Biomedicine 1(5): 391-394. https://doi. org/10.1016/S2221-1691(11)60086-5

Trineeva OV, Slivkin AI, Safonova EF (2015) Determination of hydroxycinnamic acids, carotenoids and chlorophyll in the leaves of stinging nettle (Urtica dioica L.). Chemistry of plant raw material 3: 105-110. https://doi.org/10.14258/jcprm.201503522

Grdini'c V, Vukovi 's J (2004) Prevalidation in pharmaceutical analysis Part I. Fundamentals and critical discussion. Journal of Pharmaceutical and Biomedical Analysis 35: 489-512. https://doi.org/10.1016/j. jpba.2004.02.011

Vronska LV, Demyd AYe, Ezhned MA (2016) Development of standardization methodology of elecampane rhizomes and roots (Inula helenium L.) For the hydroxycinnamic acids content. Pharmaceutical review 2: 26-31. https://journals.indexcopernicus.com/search/article?articleId=2071519

Yezerska O, Kalynyuk T, Vronska L (2013) Quantitative Determination of Hydroxycinnamic Acids in Chicory Root. Chemistry \& Chemical Technology 7(3): 247-250. https://doi.org/10.23939/chcht07.03.247

Yezerska OI, Gavrilyuk IM, Gavrilyuk OM, Nektegayev IO, Kalinyuk TG (2014) The study about hepatoprotective activity of chicory extract (Cichorium intybus L.) Current issues in pharmacy and medicine: science and practice 1(14): 20-23.

Vlasova IV, Vershinin VI, Tsypko TG (2011) Methodology of the spectrophotometric analysis of mixtures of organic substances: Nonadditivity of light absorption. Journal of Analytical Chemistry 66: 22-30. https://doi.org/10.1134/S1061934811010151

Granato D, Santos JS, Maciel LG, Nunes DS (2016) Chemical perspective and criticism on selected analytical methods used to estimate the total content of phenolic compounds in food matrices. Trends in Analytical Chemistry 80:266-279. https://doi.org/10.1016/j. trac.2016.03.010 